\title{
Aging and eye tracking: in the quest for objective biomarkers
}

\author{
Ramtin Z Marandi ${ }^{1}$ \& Parisa Gazerani*,1 \\ ${ }^{1}$ Department of Health Science \& Technology, Aalborg University, Aalborg E 9220, Denmark \\ *Author for correspondence: Tel.: +45 9940 2412; gazerani@hst.aau.dk
}

Recent applications of eye tracking for diagnosis, prognosis and follow-up of therapy in age-related neurological or psychological deficits have been reviewed. The review is focused on active aging, neurodegeneration and cognitive impairments. The potential impacts and current limitations of using characterizing features of eye movements and pupillary responses (oculometrics) as objective biomarkers in the context of aging are discussed. A closer look into the findings, especially with respect to cognitive impairments, suggests that eye tracking is an invaluable technique to study hidden aspects of aging that have not been revealed using any other noninvasive tool. Future research should involve a wider variety of oculometrics, in addition to saccadic metrics and pupillary responses, including nonlinear and combinatorial features as well as blink- and fixation-related metrics to develop biomarkers to trace age-related irregularities associated with cognitive and neural deficits.

First draft submitted: 15 June 2019; Accepted for publication: 2 September 2019; Published online: 9 October 2019

Keywords: active aging $\bullet$ aging $\bullet$ age-related deficits $\bullet$ biomarkers $\bullet$ eye tracking $\bullet$ neurodegeneration $\bullet$ neurological - oculometrics • psychological • pupillary responses

First, it is important to clear what it is meant by biomarkers. A definition by National Institute of Health for biomarker is, as states in [1], "a characteristic that is objectively measured and evaluated as an indicator of normal biological processes, pathogenic processes or pharmacologic responses to a therapeutic intervention." This broad definition has recently been reviewed in [2], attempting to provide a unified definition while advanced in terms of practical and clinical applications. The term 'biomarker' is sometimes misused, thus, to avoid confusion, it should be noted that the mentioned oculometrics in this article are potential biomarkers and have not necessarily been approved by the authorities, for example, US FDA.

\section{Aging}

Nowadays, population aging has become one of the main global concerns, especially in public health sectors. Aging has been referred to as one of the biggest challenges globally by WHO [3]. The predictions show that population of people aged $50+$ years and thereby the retirement age is growing in many developed countries [4,5]. The number of 80-year old is expected to be tripled by 2050 [3]. In addition, living independently and individualism are becoming more prevalent, which may affect psychosocial aspects of healthy aging. Thus, physical and psychological aspects of aging are concerned by some authorities to reduce the potential health-related expenses and elaborate on life quality. A potential approach is the use of e-health and tele-health to monitor and prevent age-related disorders and diseases, for example, Alzheimer's disease (AD) and Parkinson's disease (PD) [6]. Several tools and techniques have been provided to facilitate monitoring and prevention.

We have reviewed the studies published in the last decade (from 2010 to 2019) to: provide an overview the studies in relation to aging with focus on eye movements, pupillary responses and eye tracking; and to give insights into the potential applications of eye tracking to serve as a reliable tool for application in elderly in relation to neurological, cognitive and mental health. The studies regarding the loss of vision or neurological diseases that affect vision are beyond the focus of the current review. It is worth noting however that some age-related deficits 
including the loss of visual attention on the periphery or balance problems should be addressed in connection with the loss of vision [7].

Aging, as a multidimensional phenomenon [8,9], involves neurophysiological changes during the course of life. Although time is a main variable in the process of aging, it is not the only parameter contributing to aging [8,9]. Genetics and environmental factors such as diet, and physical/mental activities can influence aging. Healthy aging is defined by WHO as "the process of developing and maintaining the functional ability that enables wellbeing in older age" [10]. WHO has considered a focus on healthy aging since 2015 and the program continues to run until 2030 [10]. According to the WHO definition, functional ability consists of the intrinsic capacity of the individual, relevant environmental characteristics and the interaction between these components. Intrinsic capacity is consequently defined as mental and physical capacities of an individual that include ability to walk, think, see, hear and remember. Presence of diseases and alterations due to aging affect the intrinsic capacity. Monitoring of intrinsic activities can help in the identification of the influential factors and the preventive solutions leading to healthy aging.

Advancement in the realm of e-health and tele-health has opened up a great opportunity for monitoring and prevention plans in health sector [11-14]. E-health and tele-health have been accepted gradually in societies and are becoming a part of routine procedure around the globe. A study on 1114 Dutch participants (aged 57-77 years) has reported that more than $60 \%$ had a positive view toward e-health, exhibiting intention to learn and use such technologies [15]. Nowadays, we can have 24/7 data of our physiology (e.g., heart rate) using smartwatches and activity trackers, which is useful in the emerging area of mobile health (m-health) $[16,17]$. In the near future, these technologies may serve as medical consultants to alert people about detrimental changes to their health and whether it is needed to visit a doctor, especially helpful for the individuals prone to neurological conditions or diseases. The neurological data are not easily accessible unobtrusively and the studies are limited [18]. Thus, the research community is thriving to develop systems and methods to access such data reliably and in an unobtrusive manner, for example, using eye tracking [19].

\section{Why eye tracking?}

Eye tracking provides indirect access to the neural and cognitive processing [20]. There are a variety of techniques for eye tracking to study eye movements and pupillary responses [20,21]. A key advantage of eye tracking is the facilitation to study human neurophysiology and psychology in unobtrusive and noninvasive manner [21,22]. This means that the eye tracking (e.g., via light-weight goggles) is becoming a reliable tool to monitor health in real-life settings [19]. This offers a huge potential for the neurology community in which vital neurophysiological data can be obtained from elderly population on a daily basis for diagnosis, prognosis and monitoring. Various cortical and subcortical areas in the brain are involved in the generation and modulation of different eye movements [23]. No alternative noninvasive tool has been proposed that allows the investigation of such an extensive neural network to uncover some hidden aspects of cognitive impairments or brain injuries. Other techniques such as electroencephalography and resonance imaging provide useful information regarding the activity of the CNS and peripheral nervous system. Eye tracking can provide complementary evidence along with the other techniques [24]. Eye tracking can be used in real-time analysis of cognitive states. In addition, it provides high temporal resolution of neural processing of the brain areas that are involved in oculomotor responses. Such co-occurrence of brain activities and ocular responses have been supported by local field potential recordings [25]. These powerful features of eye tracking will be discussed in the following sections.

\section{Ocular events}

Eye movements can be analyzed based on the pupil position in the eye cavity as a function of time. This can be mapped into gaze data, where the gaze position is estimated in a visual field. The velocity of eye movements consequently can be derived using filtering schemes or simply taking derivatives from the gaze data (gaze position). Along with the gaze data, the size of the pupil is sometimes provided by eye trackers, which is used to measure pupil dilation and to detect the closure of the eyelids and thereby eye blinks. Eye movements are categorized as ocular events based on their characteristics that are briefly explained [20,21].

\section{Fixation}

Fixations are characterized with the eyes standing relatively still for a while. Fixations are vital to receive visual information. Fixation may seem to be static and stationary, but involves small imperceptible movements of the 
eyeballs, which can be classified into microsaccades, microtremors and drifts [26]. Microsaccades are involuntary saccadic-like movements during fixations, but with lower amplitudes compared with saccades [26]. Microtremors (or ocular tremors) are also fast fixational eye movements observable in the frequency range of 50-100 Hz, with a high speed of $1.5^{\circ} / \mathrm{s}$ [27]. Drifts are slow motions with the speed of about $\left(<50^{\prime} / \mathrm{s}\right)$ [27]. These three types of fixational eye movements are less studied due to technical barriers (e.g., low spatial precision) [27], which have been improved in video-based eye trackers. The role of these fixational eye movements is not very clear. A hypothesis is that they contribute to the stabilization of the retinal image $[26,28]$.

\section{Blink}

It is a short period (usually 100-400 ms) in which the eyes are covered simultaneously by the eyelids during wakefulness. It is a semiautonomic action similar to breathing where one can do it voluntarily (voluntary blink), or it can occur as a reflex to light or a mechanical touch (reflex blink) or occurring involuntarily with no external trigger (spontaneous blink). In addition to cleaning and lubrication of the surface of the cornea and the conjunctiva, it is associated with cognitive and neural processing.

\section{Saccade}

Saccades are fast eye movements to move the gaze position from one salient area to another in the visual field. Saccades are required to scan visual field because there is only a tiny part of the retina (fovea) with high density of photoreceptors that allows accurate vision [29]. Saccades can be executed to explore a visual scene (voluntary or scanning saccades) or can be generated as a response to a suddenly appeared stimulus (reactive saccades). Thus, saccades can be analyzed and studied in relation with the tasks and stimuli. Involuntary saccades may occur during sleep (rapid eye movements) [30], in the form of microsaccades, and as vestibular ocular reflex (catch-up saccades) [31,32]. There are experimental paradigms that enable different forms of saccades including express saccades with shorter latencies than other types of saccades [33]. Two of the common paradigms have been termed gap and overlap in the literature. If there is a gap (interval) between the disappearance of an initial fixation point and its successive fixation point, it is a gap paradigm. Otherwise, if there is an overlap in time for these two to occur, it is an overlap paradigm. Saccade generation circuit involves the superior colliculus in the midbrain, however, different types of saccades have been shown to be modulated by the neural areas for cognitive control [33].

\section{Vergence \& version}

The eyes move together simultaneously, which is usually to the same direction (version). The movement of the eyeballs can also be toward or away from each other (vergence) when the depth of an object that is being viewed changes [34]. The study of vergence is useful to find age-related differences. For example, longer vergence has been reported in 13 elderly individuals (aged 60-93 years) compared with ten young adults (aged 20-32 years) in a task of fixations on targets in three distances from the participants [35]. Recording vergence requires binocular eye tracking.

\section{Pursuit}

To follow a moving object in the visual field, the eyes do the (smooth) pursuit movements. Pursuit eye movements thus need an external stimulus to move with respect to the observer. The movement can be distinguished from saccades, as it has a slower and smooth movement compared with saccades.

\section{Vestibulo-ocular response/reflex}

Vestibulo-ocular movements occur to compensate for the head movements to preserve the image of the visual field on the retina. This movement works tightly with the vestibular system in the inner eye, which is responsible for self-balance, and identification of the body coordinates with respect to the external world.

\section{Optokinetic response}

Optokinetic response (OKN; nystagmus) is an involuntary eye movement, wherein the eyes appear to follow a moving object and at one point regress back. Nystagmus may be caused by congenital, idiopathic and neurological disorders, or temporary disorientation (e.g., rollercoaster) and some drugs (e.g., alcohol, lidocaine) [36]. 


Table 1. An overview of ocular events and their representative features (oculometrics) commonly used in the
literature.
\begin{tabular}{|ll|}
\hline Ocular events & Oculometrics \\
\hline Saccade & $\begin{array}{l}\text { Amplitude, duration, velocity, peak velocity-amplitude relationship (mean sequence), rate (frequency), acceleration, } \\
\text { deceleration, latency }\end{array}$ \\
\hline Fixation & Duration, rate (frequency) \\
\hline Blink & Duration, rate (frequency) \\
\hline Vergence & Velocity, amplitude, duration, latency (e.g., [35,50,51]) \\
\hline Pursuit & Root-mean-square error of gaze and target position [52], and latency (e.g., [53]) \\
\hline Vestibulo-ocular & The ratio of eye velocity to head velocity (e.g., [54,55]) \\
\hline Optokinetic response & Amplitude, duration and velocity of compensatory slow phases and saccadic quick phases of eye movements (e.g., [56]) \\
\hline Pupillary responses & $\begin{array}{l}\text { Statistical features (e.g., mean, range) of pupil diameter, latency and peak of task-evoked pupil dilations, (pupillary) index } \\
\text { of cognitive activity [57] }\end{array}$ \\
\hline
\end{tabular}

\section{Pupillary responses}

The pupils are also important source of cognitive and neural processing. The dilation and constrictions of the pupils are called pupillary responses. A common method to measure pupillary responses (pupillometry) is video-based eye tracking. This technique is widely used, but there are technical concerns that should be considered in the measurement of pupil dilations. These technical concerns can be partially solved by choosing a proper task and experimental setup. A common problem is data loss and disturbances due to the occlusion of the pupil image due to partial closure of the eyelids, make-up, contact lenses and eyeglasses. The measurement error for pupil size is likely to be higher during saccades or when the pupil goes to the corners of eye images especially in low-end eye trackers. A conservative approach is to only measure the pupil size during fixations; however, there are some methods to compensate for the errors occurring due to the position of the pupil [37,38]. In a conservative approach, the tasks should require limited eye movements to allow stable recording of the pupil size. Pupil size even during fixations may be affected by pre- and postsaccadic disturbances. Pupil dilations are also sensitive to a couple of confounding factors in addition to light [38]. The confounding effects can be avoided using short-enough trials to avoid fatigue, for example.

There are two approaches to characterize pupil-based oculometrics in connection with locus-coeruleus system. One is to measure low-frequency components (e.g., $<4 \mathrm{~Hz}$ ) of pupil size as tonic responses. The other approach is to extract high-frequency components of the pupillary responses (e.g., between 4 and $12 \mathrm{~Hz}$ ) or task-evoked responses as phasic responses. Phasic responses are less sensitive to the light and are sometimes favored to tonic responses in conditions where the light exposure cannot be controlled (e.g., [39]). This is still an open area of research on how to find reliable pupillary metrics concerning age-related differences [40].

Ocular events can be studied to assess different aspects of health, and to diagnose some abnormal conditions and diseases of neural system in early stages during the aging process. Eye movements have been shown to be affected by top-down and bottom-up processing [41-44]. Some cognitive deficiencies and perceptual abnormalities that occur in the elderly individuals may appear in ocular events.

Eye movements and pupillary responses can be quantified using standardized tasks and algorithms. An ocular event (or a combination of ocular events) can be quantified as oculometrics. Oculometrics characterize the kinematics of eye movements and pupillary responses. In addition, oculometrics can be defined in relation to the stimuli (e.g., dwell time [45,46], scanpath length [47]). There are several algorithms to identify ocular events as well as various methods to define and compute oculometrics [20,48]. Some of the oculometrics are well-established in eye movement research, for example, saccade peak velocity. Some oculometrics have been introduced in recent years and may require further studies to assess their reliability and validity [40]. Table 1 gives a summary of some useful oculometrics to study eye movements. An extensive list of 101 oculometrics analyzed in 298 healthy participants can be found in [49].

An important question is: how reliable are oculometrics? It is promising that some oculometrics are reliable, currently used in real-world applications, for example, to detect fatigue and drowsiness while driving [58], and enhance neuropsychological assessments [59]. It is a valid question to identify normal and abnormal oculomotor behavior. Oculometrics can potentially serve as biomarkers for cognitive functioning [60,61]. The reliability of oculometrics during standardized tasks appears to be high enough to hallmark neurodegeneration [62]. For example, 
the reliability of many oculometrics have been assessed in 100 healthy participants in [63], wherein the saccadic main sequence has been shown to be highly reliable in prosaccade and antisaccade tasks. In another study [64], it has been shown that the saccade latency and fixation stability in visually guided saccade tasks exhibit high reliability and good consistency. Similarly, high reliability has been observed in saccade peak velocity in [60] in prosaccade, antisaccade and memory-guided saccade tasks. In addition, fixation duration, saccade duration, saccade peak velocity and saccadic main sequence have been found to be reliable in healthy young and elderly individuals [40]. High reliability has not always been the case, one can find oculometrics, for example, saccade amplitude with poor reliability or low consistency $[65,66]$. The study on the reliability of oculometrics is limited; an overview on the reliability of oculometrics focusing on age-related changes between young and elderly adults suggests no substantial impact of age on the reliability of oculometrics [40].

To rely on oculometrics as objective biomarkers of aging and/or neurodegeneration, it is of pivotal importance to have a broad view on the source of variability of the oculometrics. One source of variation of oculometrics is the circadian rhythms [67,68]; thus, it should be controlled in clinical evaluations to avoid type I and type II errors. Another source of variability is due to measurement errors, which can be categorized into human errors in recording and analyzing data, technical deficiencies in the device (e.g., internal signal drift or accumulative delays in long recordings), and the incapability of the patient/participant to do the task properly. It is also important to note that the oculometrics can be varied by the consumption of caffeine, nicotine and drugs, including cognitive enhancers [69]. Aside from these, oculometrics may change, among others, by fatigue [70,71], emotional states [72,73], cognitive load [40,74] and environmental factors [75,76].

There are basic strategies to avoid confounding factors and irrelevant oculomotor variabilities. These strategies are useful to conduct experiments and clinical assessments. A strategy is to measure the variability of the oculometrics within a session. It can be done using multiple short recordings of the same participant in the same laboratory condition. This is useful to assess normal behavior in ocular events and to assess the reliability within a specific condition using odd-even and split-half correlations [77]. Given an estimate of the variability of oculometrics may allow valid interpretation of the observation of any significant change in oculometrics in response to an intervention or internal causal factor. Furthermore, automatized protocols (minimized human interventions) and simplified tasks with clear instructions may reduce human errors and confusions, especially if the test-retest reliability is under investigation. In addition, quality of eye trackers (e.g., accuracy and precision) should be measured empirically for different conditions based on standardized methods $[20,78]$.

\section{Eye-tracking techniques}

There are different methods to measure eye movements in relation to neurological health conditions [21,79]. There is a long list of neuro-ophthalmic examination techniques [80], which is beyond the scope of this review. Here, we focus on eye tracking and its recent contributions to the identification of age-related changes in eye movements. Three classes of eye tracking are video-based eye tracking, electrooculography (EOG) and eye-contact techniques.

\section{Video-based techniques}

This popular class of eye trackers often use high-speed cameras and image-processing algorithms to find the location of the pupil and Purkinje reflections. A common technique is based on the emission of near-infrared light to the eyes and record the reflected images, where the borderline between the pupil and the iris, and the light reflection from the front of the cornea (corneal reflection or first Pukinje image) are recorded. The relative positioning of these two helps to estimate the gaze position (requiring a calibration procedure). A dual-Purkinje eye tracking is also used to record eye movements with higher accuracy and precision, where a second reflection from the back of the lens is also recorded. Video-based eye trackers are commercially available as goggles, head-mounted, desktop-mounted and remote devices. They have advantages and disadvantages, and hence each one is appropriate for certain research studies. A key difference is in relation to the accuracy and precision of each device. The recording of eye movements with head stabilization using head/chin rest is a simple solution to cope with some technical barriers. However, it is not favored to approach high ecological validity to have unconstrained head movements as well.

There are some technical suggestions to use the proper technique and eye-tracker model [81-83]. The sampling rate of the eye tracker is important, especially if saccades are intended to be investigated. The peak velocity of saccades may reach up to $900^{\circ} / \mathrm{s}$ [84]. Some studies have shown how the sampling frequency can affect the measurement of oculometrics [85-87]. Furthermore, the precision and accuracy are important features of an eye tracker [78,88,89]. The precision of an eye tracker shows the tolerance of changes of the measured gaze positions unrelated to the 
movements of the eyes. The accuracy of an eye tracker shows how close the measured gaze position is compared with the true gaze position.

\section{Electrooculography}

In this traditional technique, electrodes are attached on the skin around the eyes to record the signal of electrooculogram, which is originated from a resting potential between the cornea and retina. This technique has been used in various clinical assessments [55,90,91]. Although EOG has high temporal resolution, its usage is limited due to the need for electrode attachments for eye movement recordings. It provides no information regarding the pupillary responses; however, it is useful to measure blinks, saccades and fixations. It also allows recording the eye movements with close eyes as a unique feature compared with the others.

\section{Eye-contact techniques}

One of the oldest techniques to study eye movements is to attach magnetic search coils (scleral search coils) on the eyes. It provides high accuracy and precision, but at the cost of invasiveness. This technique is evolving to become less invasive [92]. The high precision and accuracy allow the analysis of fixational eye movements, postsaccade oscillations.

A common issue in eye tracking (regardless of the used technique) is the arbitrary choices to compute oculometrics. For example, the detection of ocular events may require setting of some threshold values, for example, saccadic velocity threshold of $30^{\circ} / \mathrm{s}$ that is manually set either by individual researchers or based on previous studies. To address this, some algorithms and protocols have been developed to reduce manual choices and consequent bias [9396]. It is also suggested to use open-source codes and algorithms to compute oculometrics to develop biomarkers; this helps the producibility of the research. In contrast, using closed-source codes with no clear computational algorithms provided by a specific company may not allow other researchers to study the same sets of biomarkers. Commercially available software may have default algorithms and criteria, which may not necessarily be proper for a given task or experimental setup to extract ocular events and thereby oculometrics. Thus, it is recommended to do all steps of analysis on the raw data of eye tracking using standard codes and algorithms [49].

\section{Age-related changes in the eye movements}

Aging may appear as structural and functional changes reflecting in eye movements, the changes may not be as apparent as other locomotive capabilities. These changes may include cornea, lens and vitreous humor $[97,98]$. The range of abduction, adduction and elevation has been recently studied in 261 healthy participants aged 5-91 years, wherein it was found that the angle of upward gaze decreases more rapidly with age compared with horizontal and downward gaze [99]. Another study with 1000 participants includes the distribution of saccades in basic eye movement tasks [63]. Similar exploratory studies on oculometrics have also been conducted in recent years [100].

In general, it has been reported that the latency of saccades increases with age, the error rate in antisaccade task increases. However, some other oculometrics remain relatively intact by aging, for example, the gain of horizontal and vertical smooth pursuit [101]. The ability to suppress reflexive saccades decreases while saccade latency increases by aging [102]. Smooth pursuit may also exhibit age-related changes, as compensatory (catch-up) saccades appear more frequently in elderly individuals [102]. Aging seems to decrease the velocity and increase the latency of vergence eye movements [102]. The occurrence of square wave jerks appears to increase with age during fixations [102]. Many vital structures and functionalities may remain intact with age [103,104]. The existence of regenerative properties and compensatory processes in the oculomotor system have been posited to explain the robustness of some functions and structures of eye movements against senescence [105,106].

Normal aging may affect lacrimal glands [107], the anatomy of fovea [108] and the number of axons in the optic nerve [103]. The oculomotor system can also be affected by aging [98]. The supranuclear structures act upon the discharge frequency in motor neurons of the cranial nerve nuclei (III, IV and VI). Age-related alterations in these areas may have impact on rotational eye movements, for example, smooth pursuit, saccades, convergence, vestibular and optokinetic [98]. There is a strong association between the sensory information coming from the vestibular system and the proprioception system, and the oculomotor system [98]. The decreasing sensitivity of muscle spindles by age along with decreased muscle fiber population may lead to declined ocular motility [98].

The manifestation of age-related changes may affect each ocular event in different ways and knowing these changes may help to diagnose oculomotor abnormalities. The neural signaling of saccades and smooth pursuits can be respectively intervened by the frontal and parietal eye field [98]. Volitional horizontal and vertical saccades 
mediated by frontal eye field can be more affected by aging [98]. Occipital-tectal, which contributes to the generation of reflexive saccades is less affected by aging [98]. The changes in saccade latency [109] and smooth-pursuit gain [110] across different age groups are well-established, but for some others, for example, saccade peak velocity, the literature is not equivocal [111,112]. The frequency of blinks may increase with age in adults by over $100 \%$ [113]. Blinks are mediated by two neural networks of facial motor system and the oculomotor system [114]. Facial movement disorders including apraxia, and blepharospasm, which manifest at the age of greater than 50 years can be diagnosed using blinking metrics [98].

Visual cognition has also been exhibited some age-related effects [115]. The dislocation of landing targets for saccades may reveal different adaptation patterns between young and elderly individuals [116]. In addition, perceptional features, for example, orientation, parallelism and collinearity, have been found to reveal age-related differences [117]. Perceptual differences are not limited to the mentioned static features; but have been observed in motion perception [118]. Targeting multiple points may also degrade by age [119]. Center-surround contrast suppression is another example, where the age-related differences have been exhibited [120]. These age-related inefficacies are likely to be in partial association with different cortical responses for cognitive functioning, for example, working memory [121]. These findings underline the importance of the tasks to evoke different ocular events and thereby assess different neural networks and cognitive processes.

\section{Standardized tasks to study eye movements in relation to aging}

Eye movements can be assessed in constrained and unconstrained settings. In the constrained settings, the tasks that are designed to assess specific types of eye movements and thus participant/patient is allowed to execute specific eye movements. The constrained settings involve validated tasks, which may have clinical applications, for example, prosaccade and antisaccade tasks with gap and overlap paradigms. As discussed here, the tasks in the constraint settings are very useful to assess oculomotor behavior and reveal irregular functions in the execution of eye movements in the lab. In the unconstrained settings, participants are allowed to use their eyes in more natural settings (e.g., no head stabilization) to do an activity. An advantage of using eye tracking (the goggles and remote types) is the possibility of recording eye movements in 'out-of-the-lab' conditions. The tasks of this unconstrained category may vary from free viewing to the functional tasks (e.g., driving a car or working with computer).

The analysis of eye movements in free-viewing tasks usually includes visualization of gaze patterns to elucidate top-down and bottom-up behavior. An analysis on young and elderly individuals has revealed some age-related declines in naturalistic eye movements [122]. A remarkable advantage of free viewing is to collect a rich variety of ocular events; however, there is no direct control to obtain specific distributions of ocular events, for example, 20 horizontal saccades with the amplitude of $10^{\circ}$. In addition to free viewing, a vast variety of tasks have been developed to analyze visual perception and cognition [123]. One can find those tasks that have been developed to assess visual attention, some of which are under the category of visual search tasks [124,125]. Visual search tasks can be used to study age-related changes in visual attention [126]. Eye tracking is particularly useful in the assessment of attentional bias [127]. Moreover, in recent years, different tasks have been developed to acquire relevant oculometrics in association with attentional effort, vigilance, mental load and fatigue $[40,70,73,128]$. A common technique in this regard is to ask participants to do two tasks in parallel, which is known as dual tasks as opposed to single task, and is useful particularly to reveal age-related deficits [129-132]. Further computerized cognitive tests have been developed to diagnose neurodegenerative diseases associated with neural biomarkers (levels of cerebrospinal fluid) [133], where the usability of oculometrics for this purpose can also be examined. A list of the recent studies using different tasks to inspect aging effects in unconstrained settings using eye tracking is outlined in Table 2.

Regarding the tasks in constraint settings (Table 3), antisaccade, prosaccade and memory-guided saccade for their important impacts and applications in the recent aging studies are concisely reviewed. In a prosaccade task, saccades are executed to cued fixation targets, whereas in an antisaccade task, participants are instructed to execute saccades to the opposite direction of the cued fixation targets. The control of saccade inhibition (suppression) can be investigated in antisaccade task [141]. Interestingly, there are systematic variations in the cognitive control of antisaccades and prosaccades across the lifespan, for example, saccadic reaction time increases with age [141]. In addition, the antisaccade is useful to reveal decreased inhibitory control with age. This has been applied in studying disorders in association with the frontal cortex and/or basal ganglia including attention-deficit hyperactivity disorder [142,143], amyotrophic lateral sclerosis [144] and PD [145,146], for a review readers are referred to [141].

Memory-guided saccade is another basic task, wherein a fixation point and a peripheral target are shown and participants are asked to make a saccade to the peripheral target following a short period (e.g., $2.5 \mathrm{~s}$ ) after that the 
Table 2. An overview of the recent studies (sorted by the year of publication) using video-based eye tracking in unconstrained settings that involve elderly individuals.

\begin{tabular}{|c|c|c|c|c|}
\hline Study (year) & Task & Measures & Application & Ref. \\
\hline $\begin{array}{l}\text { Yamada and Kobayashi } \\
\text { (2018) }\end{array}$ & $\begin{array}{l}\text { Watching video clips and } \\
\text { mathematical operations }\end{array}$ & $\begin{array}{l}\text { Saccades, blinks, fixations, pupillary } \\
\text { responses }\end{array}$ & Fatigue classification & [134] \\
\hline Marandi et al. (2018) & $\begin{array}{l}\text { Prolonged cyclic pattern replication } \\
\text { task }\end{array}$ & $\begin{array}{l}\text { Saccades, blinks, fixations, pupillary } \\
\text { responses }\end{array}$ & Fatigue detection in computer work & [70] \\
\hline Marandi et al. (2018) & Five minutes pattern replication task & $\begin{array}{l}\text { Saccades, blinks, fixations, pupillary } \\
\text { responses }\end{array}$ & Detection of mental load & [40] \\
\hline Stuart et al. (2018) & Walking (single and dual tasks) & Saccades & Fall prevention in Parkinson's disease & [135] \\
\hline Bergstrom et al. (2013) & Web browsing & $\begin{array}{l}\text { Duration and frequency of gaze to the } \\
\text { areas of interest }\end{array}$ & Website navigation performance & [136] \\
\hline $\begin{array}{l}\text { Merat and Jamson } \\
(2013)\end{array}$ & Simulated driving & Blinks, PERCLOS & Fatigue detection in driving & [137] \\
\hline $\begin{array}{l}\text { Hüttermann et al. } \\
\text { (2012) }\end{array}$ & $\begin{array}{l}\text { Counting specific targets in the } \\
\text { periphery and free gaze }\end{array}$ & Fixation (attention bias) & $\begin{array}{l}\text { Measuring attention in visual } \\
\text { periphery }\end{array}$ & [138] \\
\hline Allard et al. (2010) & Viewing face images & Pupillary response & $\begin{array}{l}\text { Emotion recognition and cognitive } \\
\text { effort detection }\end{array}$ & [139] \\
\hline Piquado et al. (2010) & Memory recall to auditory stimuli & Pupillary responses & Measurement of cognitive effort & [140] \\
\hline
\end{tabular}

Table 3. An overview of the recent studies (sorted by the year of publication) using video-based eye tracking in constrained settings that involve elderly individuals.

\begin{tabular}{|c|c|c|c|c|}
\hline Study (year) & Task & Measures & Application & Ref. \\
\hline Brooks et al. (2017) & Antisaccade and prosaccade tasks & Saccades & $\begin{array}{l}\text { Early differentiation between multiple system } \\
\text { atrophy and Parkinson's disease }\end{array}$ & [147] \\
\hline Shakespeare et al. (2015) & $\begin{array}{l}\text { Fixation for } 10 \mathrm{~s} \text {, gap and overlap } \\
\text { paradigms, sinusoidal pursuit }\end{array}$ & Saccades, pursuit & $\begin{array}{l}\text { Diagnosis of posterior cortical atrophy from } A D \\
\text { and healthy controls }\end{array}$ & [148] \\
\hline Bowling and Draper (2013) & $\begin{array}{l}\text { Antisaccade and oculomotor capture } \\
\text { tasks }\end{array}$ & Saccades & Early detection of cognitive decline & [149] \\
\hline Alichniewicz et al. (2013) & Antisaccade and prosaccade tasks & Saccades & $\begin{array}{l}\text { Diagnosis of aMCl and distinguish between } \\
\text { different types of dementia and other forms of } \\
\text { degenerative disorders }\end{array}$ & [150] \\
\hline Yang et al. (2013) & $\begin{array}{l}\text { Prosaccades in gap and overlap } \\
\text { paradigms }\end{array}$ & Saccades & Follow-up tests for $\mathrm{aMCl}$ and $\mathrm{AD}$ patients & [151] \\
\hline
\end{tabular}

peripheral target was disappeared. The latency of saccades to the targets and the distance of the landing locations of the saccades to the actual target locations are measured typically for many trials. This is the task through which cognitive deficits of normal aging, for example, forgetfulness and distractibility can be examined [152].

There are simple tasks but quite informative about fixations, referred to as fixation stability tests [153,154]. Fixation stability tests can be performed by keep looking on a fixation target for a specific period. Fixation stability can be measured in terms of the number of microsaccades, the length of scanpath and the duration of fixation [153]. This task is useful to reveal oculomotor deficits, for example, in schizophrenia [153,154].

In addition to the tasks developed for inspection of saccadic eye movements, researchers have developed different tasks to examine other ocular events. Smooth pursuit can be measured in standardized tasks, for example application of specific oculometrics extracted from smooth pursuit to study schizophrenia [52]. Furthermore, vestibulo-ocular response/reflex can be investigated in standardized protocols where participants are typically exposed to sinusoidal or stochastic whole-body motions [155]. Similarly, for OKN, researchers can find proper tools and tasks to induce OKN $[156,157]$.

Pupillary responses have been studied in a variety of tasks. Each group of tasks has been identified to involve a specific component of cognitive control [158]. It includes updating (e.g., the n-back task), shifting (e.g., a number switch task [159]) and inhibition (e.g., antisaccade task); more tasks in each category described in [158]. This categorization has been beneficial to better explain different findings in the pupillary responses. Typically, the 
review of the studies involving these tasks may support the increase of the pupil dilation in response to the task demands. In this categorization, the tasks that are proper to study the behavior of elderly individuals based on pupil dilations are more evident. For example, the Sternberg task, from the category of the updating component, may not reveal workload-based pupil dilations in the elderly individuals as it does for young individuals [158].

\section{Oculometrics as objective biomarkers in aging research}

Eye tracking has been reviewed in [160] and been suggested for diagnosis and follow-up of treatments of many neurodegenerative conditions. The role of eye tracking in neurodegenerative diseases including AD, Huntington disease (HD) and PD are briefly outlined here.

$\mathrm{AD}$ is a prevalent neurodegenerative disease, which has been studied using eye tracking [62,151,161-163]. AD has been found to alter pupillary responses to light stimuli [161,164-166]; however, there are mixed evidence on an association between $\mathrm{AD}$ and pupillary responses [161]. In addition, saccades have been reported to be useful to diagnose $\mathrm{AD}$. For example, in the antisaccade task, longer latency has been evidenced in $\mathrm{AD}$ patients compared with healthy controls [165]. Furthermore, microsaccades have been reported to occur more frequently in AD patients compared with healthy controls [165]. The assessment of the effect of AD on oculometrics in long term (e.g., 1 year) may reveal inconsistencies in some oculometrics (e.g., saccade amplitude and reaction time) [167]. AD seems to affect smooth pursuit as well, in which slower initiation of eye movements to follow a moving target has been reported in $\mathrm{AD}$ compared with healthy individuals [165]. In sum, eye tracking has been suggested to be used to explore the traces of $\mathrm{AD}$ that may appear many years prior to the clinical diagnosis of $\mathrm{AD}$, which may offer remarkable benefits for early diagnosis or treatment of the disease [168].

Oculometrics have also been found beneficial as objective biomarkers in prognosis, diagnosis and therapy of HD [169]. The latency and error rate of horizontal and vertical saccades in pro- and antisaccade tasks can be used as potential biomarkers for HD [169]. Furthermore, such biomarkers may be used with machine learning techniques to detect the premanifest individuals carrying the HD mutation and affected individuals from healthy controls [170]. These findings may support the usability of oculometrics as biomarkers of HD at early stages, which is important to determine a proper plan for, for example, pharmacological interventions.

Eye tracking has been found promising concerning PD. Saccade latency is associated with the brain regions that are affected in PD [171]. It has been found that the variability of saccade latency is negatively correlated with the gray matter volume of the frontal and parietal eye fields [171], which are involved in the saccade generation [172-174]. Saccades can reveal cognitive impairments in attentional deficits, which is common in, for example, dementia, but also can provide information regarding motor dysfunction in, for example, PD. In follow-up of treatments, eye tracking has been successfully utilized to assess the therapeutic effects of dopaminergic medications [175] and deep brain stimulation of the subthalamic nucleus [176-179] in patients with PD. A recent training protocol has been proposed to improve voluntary saccades in patients with PD [180].

Clinical examinations of eye movements are useful to improve diagnosis. Some neurodegenerative diseases mainly involve motor impairments, for example, in multiple system atrophy. However, if the neurodegeneration is expected to impair cognition, for example, in $\mathrm{AD}, \mathrm{HD}$ and frontotemporal dementia, then eye movements are suggested to be recorded and inspected to find distinguishing biomarkers. Saccadic metrics have been suggested as objective biomarkers of neurodegeneration for the diagnosis and keeping track of the progression of the neurodegenerative diseases. For example, increased antisaccade error and slowed prosaccade may serve as a biomarker to differentiate in early stages between PD and multiple system atrophy [147]. In addition, the performance of antisaccade task may help to measure the progression of multiple system atrophy [147]. Thus, it is seemingly useful to define features as combinations of ocular events (e.g., the proportion of short fixations succeeding long saccades) to develop biomarkers. The combinatorial features may provide additional information to describe the dynamics of eye movements [71,181].

There are common abnormalities in oculomotor behavior among the patients with PD, multiple system atrophy, progressive supranuclear palsy and corticobasal syndrome [182]. It is expected to detect mild motor impairments in smooth pursuit and OKN. The presence of saccade inaccuracies has been found in PD, multiple system atrophy, progressive supranuclear palsy and corticobasal syndrome [182]. Some abnormalities such as apraxia (increased latency) of saccades are expected to appear only in corticobasal syndrome among all mentioned disorders [182]. These results may suggest that to differentiate similar conditions, multiple biomarkers may be required.

So far, recent studies attempting to find irregularities in eye movements and pupillary responses with regard to $\mathrm{AD}, \mathrm{HD}$ and $\mathrm{PD}$ have been briefly discussed. The following subsections are the categories of prevalent health issues 
in elderly individuals, where eye tracking has been found useful to address these problems and are potential areas to further develop biomarkers based on eye-tracking data. The main idea in the following discussion is to see how eye tracking can be used for active aging.

\section{Balance}

A prevalent issue with aging is gradual decline in the control of limbs, leading to compromised balance and increased risk of falling [183]. Saccadic metrics can be used to assess the training programs for fall prevention in elderly individuals [184]. The age-related deficits may originate from the degradation of visual perception of the depth and distance in relation to the obstacles on sideways $[185,186]$.

In addition, oculomotor assessments can be used to test the vestibular function in association with balance [187]. Age-related deficits can be reflected in saccade, smooth pursuit and OKN, especially over the age of 60 and 70 years [111,187-190]. Aging is associated with decreased gain of the vestibule-ocular reflex [191]. This decrease has been evidenced to be compensated by catch-up saccades. The amplitude of these compensatory saccades has been deemed as useful oculometrics to characterize vestibular function in relation to aging [191].

\section{Hearing}

Elderly individuals may have more difficulties understanding conversations in noisy situations than young individuals [192]. In this regard, eye tracking has been found useful to study speech processing across the life span [192]. As such, it has been found from pupil dilation that it is more effortful to comprehend spoken sentences by elderly adults compared with young adults [193]. Eye fixation is useful to objectively evaluate speech processing in middle-aged and elderly individuals [194]. Sound localization deteriorates with aging [195]. Enhanced visual perception using eye tracking may facilitate sound localization in elderly individuals [196].

\section{Sleeping}

Eye movement research has also been recruited in the study of aging impacts on sleeping. Sleep quality can be quantified using polysomnography, which includes recording of eye movements through EOG to detect sleep stages [197], for example, rapid-eye movement (REM) sleep versus non-REM sleep. There is evidence that the pattern of sleeping varies with age. Elderly adults tend to sleep less and awaken more frequently than young adults [198]. There is an association between decreased slow wave activity in non-REM sleep and impaired long-term retention of episodic memories, which may develop due to aging in elderly population [199]. This is further useful to assess REM sleep behavior in elderly in connection with cognitive decline or neurodegenerative disorders such as Parkinsonism [200]. As such, idiopathic REM is suggested as an early sign to diagnose PD [201]. Sleep quality in young and middle-aged adults plays an important role in the prevention of cognitive declines [202].

\section{Stress \& anxiety}

Stress and anxiety are highly prevalent [203]. Elderly individuals, especially those above 60 years [204], are more vulnerable to stress and anxiety due to loneliness and other contributing factors, for example, hormonal variations. Among all, chronic stress is suspected to accelerate the process of aging [205]. Thus, there is a growing area of research to find biomarkers for oxidative and nitrosative stress, which are speculated to accelerate aging [206]. The eye movement research in this area may provide more evidence in the association between stress and anxiety from one side with age-related disorders and diseases, for example, $\mathrm{AD}$ on the other side [207].

In [208], a number of potential biomarkers for oxidative stress have been assessed in association with neurocognitive impairment, in which the time ratio of REM has been found useful to be significantly correlated with the mild cognitive impairment. In addition, some properties of REM sleep have been proposed as the biomarkers for prognosis of post-traumatic stress disorder (PTSD) and the trauma-related psychiatric disorders [209]. The eyemovement desensitization and reprocessing, developed by Shapiro [210] in 1990s, is currently a common clinical protocol to treat PTSD. The technique is developed to fade or disturb the memories associated with PTSD via specific patterns of eye movements during memory recall. Using eye tracking, the quality of therapies can be assessed based on the quantification of eye movements in relation to subjective evaluations to reduce stress and anxiety [211,212]. 


\section{Cognition \& cognitive ergonomics}

Eye tracking plays an important role to our understanding of memory [213,214], attention [136] and decisionmaking [215]. Using eye tracking to infer about cognitive processes not only facilitates the theoretical and fundamental studies but also has empirical application concerning the issue of aging, for example, in safe driving [216].

All types of ocular events may contain cognitive information. Fixations can be used as a measure to study spatial memory in young and elderly adults $[213,217]$. Spatial memory is a cognitive ability, for example, in navigation to find a pathway between two geographical locations [218,219] that is negatively affected by aging [220]. The age-related gradual loss in the ability of auditory localization has also been studied using fixations [221]. The study of pupillary responses in a multiobject tracking task has revealed stroke-related cognitive deficits in addition to impairments in spatial attention [222].

It is also quite interesting to see how eye tracking can reveal age-related changes of emotion [223]. Young adults have been shown to identify facial expressions better than elderly adults [224]. Eye tracking helps to infer about perceptual strategies and age-related difficulties of encoding visual data [225]. For example, to analyze visual inspection of faces, the time spent looking at upper parts of the faces, for example, eye brow, eyes, forehead wrinkles, in comparison to the lower parts, for example, lips can be measured [224]. Eye movements are also an important modality to develop emotional aspects of human-machine interactions that can be useful for the daily care for elderly individuals.

Another application of eye tracking lies within cognitive ergonomics [226] and neuroergonomics [227,228] to adjust the usability properties of devices based on the cognitive capacities of human in different ages. The current focus on the issue of aging is beyond physical declines [229-231]. Eye tracking plays an important role in neuroergonomics to model age-related variations in human-machine interactions [227], to improve the console interface design for elderly individuals. It is an area that the eye-tracking technology is used to measure mental (cognitive) load of performing a task [232-234]. This area is aimed to impede fatigue to reduce human errors and thereby enhancing productivity $[71,235]$.

\section{Pain}

Oculometrics may also be used as potential biomarkers of pain, for example, to reveal attentional bias towards pain stimuli [236] and pain management and distraction [237-239]. Valid and reliable tools have been suggested to assess pain in elderly individuals [240]. Given the pain-related applications and the prevalence of pain among elderly individuals [240], further research may reveal the oculometrics that can serve as objective biomarkers of pain.

\section{Mental disorders: schizophrenia, schizotypal \& delusional disorders}

Although schizophrenia normally begins at young adulthood around the age of 30 years or earlier, it is considered a chronic long-life mental disorder, a causal factor of disability in youth and elderly [241], and it is associated with obesity, poor diet, sedentary lifestyles and smoking [242-244]. Eye tracking can be used to assess the treatments of the disorder $[153,154]$. The assessment of the disorder may involve standardized tests for smooth pursuit, fixation stability and scanpath [153]. Eye tracking also helps to find distinctive features to classify Schizophrenia from other mental disorders, for example, obsessive compulsive disorder [154]. In addition, antisocial personality disorder, drug consumptions (including alcohol, cocaine and heroin [245]), dyslexia, autism, the acquired immunodeficiency syndrome dementia complex are among other mental disorders, where eye tracking is beneficial for diagnosis [246]. Smooth pursuit is indeed relevant to detect many of the mental disorders [246].

\section{Conclusion}

The current findings support the high impact of eye tracking as a powerful tool to provide objective biomarkers to assist healthy aging, diagnosis of the disorders and diseases associated with aging, and neurodegeneration, follow-up of disease progression and therapy effectiveness, and possibly reversing some age-related deficits. The development of oculometrics as biomarkers for aging requires technical knowledge to properly use eye tracking. Practical implications toward the use of oculometrics as potential objective biomarkers of neurological or psychological deficits among elderly individuals have been provided. Although many studies have found eye tracking to be a useful tool in aging research, the eye-tracking studies are still limited concerning unconstrained (natural) settings. Less-explored oculometrics (e.g., nonlinear and combinatorial features) and blink- and fixation-related metrics to develop biomarkers are suggested to be explored pertaining to the aging issues. 


\section{Future perspective}

Given the findings, future research to develop biomarkers for aging and neurodegeneration is facilitated. As an important application, eye tracking can be applied to counteract aging effects via increased neuroplasticity, which has been successfully applied for active aging [247], cognitive rehabilitation [248] and oculomotor training in mild traumatic brain injury [249]. Eye-tracking studies on young and elderly individuals have provided normative values for some oculometrics $[40,250]$. This may help finding irregularities in eye movements due to a disease or disorder, and thereby going through the standard procedures for verification of sensitivity, specificity and reliability of the oculometrics as objective biomarkers. A strategy to develop oculometrics as biomarkers is to identify currently used biomarkers of neurodegenerative diseases [251,252], their benefits (e.g., accuracy and specificity) and drawbacks (e.g., invasiveness and costs), and whether eye tracking can provide comparable alternatives.

Advanced statistical methods and machine-learning tools are required to accurately detect abnormalities occurring in a number of oculometrics. In this view, a set of relevant oculometrics may be considered as potential objective biomarker identifying a neurodegenerative disease or to support clinical decisions.

Furthermore, it appears that the current sets of oculometrics that have been used in the literature are very limited. A great body of the research on age-related alterations of eye movements has been dedicated to the study of saccades and pupillary responses. It is thus suggested to use broader categories of oculometrics as biomarkers, since they may convey complementary psychophysiological information. Further to the combinatorial features mentioned earlier, an informative class of features are nonlinear features [40,253-258]. The interpretation of nonlinear features, however, may not be as easy as coarse-grained features such as the frequency of saccades. The reliability of nonlinear features from eye movements and pupillary response are required to be studied [40].

A multidisciplinary view may ease the speculation on the applications of eye tracking. The current era has witnessed revolutionary advancements in different fields including eye tracking thanks to the hardware and software advances. These progresses arise the idea of ubiquitous healthcare, in which portable devices play key roles in the acquisition of biosignals [259], which can be beneficial for active aging and to prevent age-related defects. The internet of medical (or health) things [260-264], quantum computing [265-267] and the fifth-generation cellular network technology in healthcare [268,269] are the areas, where eye tracking can be thought of as an important modality for active aging. It is important to take the most out of these technologies and frameworks to better serve the elderly individuals concerning the population aging [270].

\section{Executive summary}

- Current literature supports the notion that eye tracking can serve as a powerful tool to provide valuable information on healthy or unhealthy aging process.

- Eye tracking provides oculometrics that can be used as biomarkers for aging, but this idea requires technical knowledge to properly use eye tracking and to interpret outcomes.

- Eye-tracking studies on young and elderly individuals have provided normative values for some oculometrics.

- Oculometrics not only can assist in understanding of healthy aging process but also can help with diagnosis of disorders and diseases associated with aging and neurodegeneration, and follow-up of disease progression and responsiveness or lack of that to therapeutic strategies.

- Less-explored oculometrics (e.g., nonlinear and combinatorial features) and blink- and fixation-related metrics are suggested to be employed in future investigations of aging related issues.

- It is also proposed to apply unconstrained (natural) settings as much as possible for ecological validity when oculometrics are used.

- A strategy to develop oculometrics as objective biomarkers is to identify currently used biomarkers of neurodegenerative diseases, their benefits (e.g., accuracy and specificity) and drawbacks (e.g., invasiveness and costs) and whether eye tracking can provide comparable alternatives. 
Financial \& competing interests disclosure

The authors have no relevant affiliations or financial involvement with any organization or entity with a financial interest in or financial conflict with the subject matter or materials discussed in the manuscript. This includes employment, consultancies, honoraria, stock ownership or options, expert testimony, grants or patents received or pending, or royalties.

No writing assistance was utilized in the production of this manuscript.

\section{Open access}

This work is licensed under the Attribution-NonCommercial-NoDerivatives 4.0 Unported License. To view a copy of this license, visit http://creativecommons.org/licenses/by-nc-nd/4.0/

\section{References}

Papers of special note have been highlighted as: $\bullet$ of interest; $\bullet \bullet$ of considerable interest

1. Strimbu K, Tavel JA. What are biomarkers? Curr. Opin. HIV AIDS 5(6), 463 (2010).

2. Califf RM. Biomarker definitions and their applications. Exp. Biol. Med. 243(3), 213-221 (2018).

-. This reference provides definitions for biomarkers.

3. Garde E. Healthy aging. University of Copenhagen (2017). https://healthsciences.ku.dk/about/impact/healthy-aging/

4. United Nations Department of Economic and Social Affairs. World Population Prospects: The 2017 Revision (2017). https://www.un.org/development/desa/publications/world-population-prospects-the-2017-revision.html

5. He W, Goodkind D, Kowal PR. An Aging World: 2015. United States Census Bureau, Washington, DC, USA (2016).

6. Peek STM, Luijkx KG, Rijnaard MD et al. Older adults' reasons for using technology while aging in place. Gerontology 62(2), 226-237 (2016).

7. Wood JM, Lacherez P, Black AA, Cole MH, Boon MY, Kerr GK. Risk of falls, injurious falls, and other injuries resulting from visual impairment among older adults with age-related macular degeneration. Invest. Ophthalmol. Vis. Sci. 52(8), 5088-5092 (2011).

8. Anderson BB, Brodowsky GH. Chronological age versus life horizon: exploring the concept of ageing in consumer behavior. J. Mark. Dev. Compet. 9(2), 27 (2015).

9. Mathur A, Moschis GP. Antecedents of cognitive age: a replication and extension. Psychol. Mark. 22(12), 969-994 (2005).

10. Doan C. What is healthy ageing? WHO/WPRO (2017). https://www.who.int/ageing/healthy-ageing/en/

11. Sardi L, Idri A, Fernández-Alemán JL. A systematic review of gamification in e-Health. J. Biomed. Inform. 71, 31-48 (2017).

12. Rahmani AM, Gia TN, Negash B et al. Exploiting smart e-Health gateways at the edge of healthcare internet-of-things: a fog computing approach. Futur. Gener. Comput. Syst. 78, 641-658 (2018).

13. Robbins TD, Keung SNLC, Arvanitis TN. E-health for active ageing: a systematic review. Maturitas. 114, 34-40 (2018).

14. Zhu N, Diethe T, Camplani M et al. Bridging e-health and the internet of things: the sphere project. IEEE Intell. Syst. 30(4), 39-46 (2015).

15. de Veer AJ, Peeters JM, Brabers AE, Schellevis FG, Rademakers JJ, Francke AL. Determinants of the intention to use e-Health by community dwelling older people. BMC Health Serv. Res. 15(1), 103 (2015).

16. Adibi S. Mobile Health: A Technology Road Map (1st Edition). Springer International Publishing, AG, Cham, Switzerland (2015). http://dro.deakin.edu.au/view/DU:30072528

17. Steinhubl SR, Muse ED, Topol EJ. The emerging field of mobile health. Sci. Transl. Med. 7(283), 283rv3-283rv3 (2015).

18. Vázquez A, Jenaro C, Flores N, Bagnato MJ, Pérez MC, Cruz M. E-health interventions for adult and aging population with intellectual disability: a review. Front. Psychol. 9,2323 (2018).

19. Esteves A, Velloso E, Bulling A, Gellersen H. Orbits: gaze interaction for smart watches using smooth pursuit eye movements. In: Proceedings of the 28th Annual ACM Symposium on User Interface Software \& Technology. NC, USA, 457-466 (2015). https://dl.acm.org/citation.cfm?id=2807442

20. Holmqvist K, Nyström M, Andersson R, Dewhurst R, Jarodzka H, de Weijer J. Eye Tracking: A Comprehensive Guide to Methods and Measures. Oxford University Press, Oxford, UK (2011).

-. This reference provides guidelines to use proper methods in eye tracking.

21. Leigh RJ, Zee DS. The Neurology of Eye Movements. Oxford University Press, Oxford, UK (2015).

22. Tonsen M, Steil J, Sugano Y, Bulling A. Invisibleeye: mobile eye tracking using multiple low-resolution cameras and learning-based gaze estimation. ACM IMWUT 1(3), 106 (2017).

23. Byrom B, McCarthy M, Schueler P, Muehlhausen W. Brain monitoring devices in neuroscience clinical research: the potential of remote monitoring using sensors, wearables, and mobile devices. Clin. Pharmacol. Ther. 104(1), 59-71 (2018). 
24. Samadani U. Will eye tracking change the way we diagnose and classify concussion and structural brain injury? Concussion 1(1), 1-3 (2016).

25. Schwalm M, Jubal ER. Back to pupillometry: how cortical network state fluctuations tracked by pupil dynamics could explain neural signal variability in human cognitive neuroscience. eNeuro 4(6), ENEURO.0293-16.2017 (2017).

26. Martinez-Conde S, Macknik SL, Hubel DH. The role of fixational eye movements in visual perception. Nat. Rev. Neurosci. 5(3), 229-240 (2004).

27. Ko HK, Snodderly DM, Poletti M. Eye movements between saccades: measuring ocular drift and tremor. Vision Res. 122, 93-104 (2016).

28. Poletti M, Aytekin M, Rucci M. Head-eye coordination at a microscopic scale. Curr. Biol. 25(24), 3253-3259 (2015).

29. Purves D, Augustine G, Fitzpatrick D et al. Neuroscience (2nd Edition). Sinauer Associates, MA, USA (2001). https://www.ncbi.nlm.nih.gov/books/NBK10991/

30. Andrillon T, Nir Y, Cirelli C, Tononi G, Fried I. Single-neuron activity and eye movements during human REM sleep and awake vision. Nat. Commun. 6, 7884 (2015).

31. Yacovino DA, Martin LA, Akly MP, Hain TC. Characteristics of vestibular corrective saccades in patients with slow visual saccades, vestibular disorders and controls: a descriptive analysis. PLoS ONE 13(5), e0197079 (2018).

32. Weber KP, Aw ST, Todd MJ, McGarvie LA, Curthoys IS, Halmagyi GM. Head impulse test in unilateral vestibular loss: vestibulo-ocular reflex and catch-up saccades. Neurology 70(6), 454-463 (2008).

33. Hutton SB. Cognitive control of saccadic eye movements. Brain Cogn. 68(3), 327-340 (2008).

34. Cassin B, Solomon S, Rubin ML. Dictionary of Eye Terminology (1st Edition). Triad Pub. Co, FL, USA (1984). https://www.triadpublishing.com/contactus.shtml

35. Sander T, Sprenger A, Neumann G et al. Vergence deficits in patients with cerebellar lesions. Brain 132(1), 103-115 (2008).

36. Leigh J, Zee DS. The neurology of eye movements. J. Chem. Inf. Model. 53(9), 1689-1699 (2013).

37. Choe KW, Blake R, Lee S-H. Pupil size dynamics during fixation impact the accuracy and precision of video-based gaze estimation. Vision Res. 118, 48-59 (2016).

38. Knapen T, De Gee JW, Brascamp J, Nuiten S, Hoppenbrouwers S, Theeuwes J. Cognitive and ocular factors jointly determine pupil responses under equiluminance. PLoS ONE 11(5), e0155574 (2016).

39. Peysakhovich V, Vachon F, Dehais F. The impact of luminance on tonic and phasic pupillary responses to sustained cognitive load. Int. J. Psychophysiol. 112, 40-45 (2017).

40. Marandi RZ, Madeleine P, Omland Ø, Vuillerme N, Samani A. Reliability of oculometrics during a mentally demanding task in young and old adults. IEEE Access. 6, 17500-17517 (2018).

41. Gilbert CD, Li W. Top-down influences on visual processing. Nat. Rev. Neurosci. 14(5), 350 (2013).

42. Zelinsky GJ, Zhang W, Yu B, Chen X, Samaras D. The role of top-down and bottom-up processes in guiding eye movements during visual search. In: Advances in Neural Information Processing Systems. MIT Press, MA,

USA, 1569-1576 (2006). https://papers.nips.cc/book/advances-in-neural-information-processing-systems-18-2005

43. Malcolm GL, Henderson JM. Combining top-down processes to guide eye movements during real-world scene search. J. Vis. 10(2), 4 (2010).

44. Katsuki F, Constantinidis C. Bottom-up and top-down attention: different processes and overlapping neural systems. Neuroscientist. 20(5), 509-521 (2014)

45. Rösler A, Ulrich C, Billino J et al. Effects of arousing emotional scenes on the distribution of visuospatial attention: changes with aging and early subcortical vascular dementia. J. Neurol. Sci. 229, 109-116 (2005).

46. Knight M, Seymour TL, Gaunt JT, Baker C, Nesmith K, Mather M. Aging and goal-directed emotional attention: distraction reverses emotional biases. Emotion 7(4), 705 (2007).

47. Haass MJ, Matzen LE, Butler KM, Armenta M. A new method for categorizing scanpaths from eye tracking data. In: Proceedings of the Ninth Biennial ACM Symposium on Eye Tracking Research \& Applications. ACM, NY, USA, 35-38 (2016). https://dl.acm.org/citation.cfm?id=2857491

48. Duchowski A. Eye Tracking Methodology Theory and Practice (3rd Edition). Springer, Cham, Switzerland (2007). https://www.springer.com/gp/book/9781846286087

- This reference provides guidelines in the methodology in eye tracking.

49. Rigas I, Friedman L, Komogortsev O. Study of an extensive set of eye movement features: extraction methods and statistical analysis. J. Eye Mov. Res. 11(1), 3 (2018).

- This reference is a useful resource to extract various eye movement features.

50. Vienne C, Sorin L, Blondé L, Huynh-Thu Q, Mamassian P. Effect of the accommodation-vergence conflict on vergence eye movements. Vision Res. 100, 124-133 (2014). 
51. Coubard OA. Saccade and vergence eye movements: a review of motor and premotor commands. Eur. J. Neurosci. 38(10), 3384-3397 (2013).

52. O'Driscoll GA, Callahan BL. Smooth pursuit in schizophrenia: a meta-analytic review of research since 1993. Brain Cogn. 68(3), 359-370 (2008).

53. Spering M, Montagnini A. Do we track what we see? Common versus independent processing for motion perception and smooth pursuit eye movements: a review. Vision Res. 51(8), 836-852 (2011).

54. Mantokoudis G, Saber Tehrani AS, Kattah JC et al. Quantifying the vestibulo-ocular reflex with video-oculography: nature and frequency of artifacts. Audiol. Neurotol. 20(1), 39-50 (2015).

55. Li C, Layman AJ, Geary R et al. Epidemiology of vestibulo-ocular reflex function: data from the Baltimore Longitudinal study of aging. Otol. Neurotol. 36(2), 267-272 (2015).

56. Waddington J, Harris CM. Human optokinetic nystagmus and spatial frequency. J. Vis. 15(7), 1-16 (2015).

57. Marshall SP. The index of cognitive activity: measuring cognitive workload. In: Proceedings of the IEEE 7th conference on Human Factors and Power Plants. IEEE, AZ, USA, 5-9 (2002). https://ieeexplore.ieee.org/document/1042860

58. Victor T, Kronberg P. Method and apparatus for determining and analyzing a location of visual interest. US Patent 8,487,775 (2013). https://scholar.google.se/citations? user=pXo-RL8AAAAJ\&hl=en

59. Ettenhofer ML, Barry D. Enhanced neuropsychological assessment with eye tracking. Patent: EP2991541A4 (2016). https://patents.google.com/patent/EP2991541A4/en

60. Meyhöfer I, Bertsch K, Esser M, Ettinger U. Variance in saccadic eye movements reflects stable traits. Psychophysiology 53(4), 566-578 (2016).

61. Turner TH, Renfroe JB, Duppstadt-Delambo A, Hinson VK. Validation of a behavioral approach for measuring saccades in Parkinson's disease. J. Mot. Behav. 49(6), 657-667 (2017).

62. MacAskill MR, Anderson TJ. Eye movements in neurodegenerative diseases. Curr. Opin. Neurol. 29(1), 61-68 (2016).

63. Bargary G, Bosten JM, Goodbourn PT, Lawrance-Owen AJ, Hogg RE, Mollon J. Individual differences in human eye movements: an oculomotor signature? Vision Res. 141(2017), 157-169 (2017).

- This reference provides an extensive study on the reliability of oculometrics.

64. Vikesdal GH, Langaas T. Saccade latency and fixation stability: repeatability and reliability. J. Eye Mov. Res. 9(2)(3), 1-13 (2016).

65. Bollen E, Bax J, Van Dijk JG et al. Variability of the main sequence. Investig. Ophthalmol. Vis. Sci. 34(13), 3700-3704 (1993).

66. Stuart S, Alcock L, Godfrey A, Lord S, Rochester L, Galna B. Accuracy and re-test reliability of mobile eye-tracking in Parkinson's disease and older adults. Med. Eng. Phys. 38(3), 308-315 (2016).

67. Schalén L, Pyykkö I, Juhola M, Magnusson M, Jäntti V, Henriksson N. Intra-individual variation in oculomotor performance in man. Acta Otolaryngol. 96(Suppl. 406), 212-217 (1983).

68. Cazzoli D, Antoniades CA, Kennard C, Nyffeler T, Bassetti CL, Müri RM. Eye movements discriminate fatigue due to chronotypical factors and time spent on task - a double dissociation. PLoS ONE 9(1), e87146 (2014).

69. Reilly JL, Lencer R, Bishop JR, Keedy S, Sweeney JA. Pharmacological treatment effects on eye movement control. Brain Cogn. 68(3), 415-435 (2008).

70. Marandi RZ, Madeleine P, Omland Ø, Vuillerme N, Samani A. Eye movement characteristics reflected fatigue development in both young and elderly individuals. Sci. Rep. 8(1), 13148 (2018).

71. Marandi RZ, Madeleine P, Omland Ø, Vuillerme N, Samani A. An oculometrics-based biofeedback system to impede fatigue development during computer work: a proof-of-concept study. PLoS ONE 14(5), e0213704 (2019).

72. Scott GG, O’donnell PJ, Sereno SC. Emotion words affect eye fixations during reading. J. Exp. Psychol. Learn. Mem. Cogn. 38(3), 783 (2012).

73. Marandi RZ, Ann Fjelsted C, Hrustanovic I, Dan Olesen R, Gazerani P. Association between cognitive load, affective pain perception and eye movements. IEEE Transactions on Affective Computing (under review: manuscript ID is TAFFC-2019-02-0058) (2019).

74. Valtchanov D, Ellard CG. Cognitive and affective responses to natural scenes: effects of low level visual properties on preference, cognitive load and eye-movements. J. Environ. Psychol. 43, 184-195 (2015).

75. Wilkins AJ. A physiological basis for visual discomfort: application in lighting design. Light. Res. Technol. 48(1), 44-54 (2016).

76. Paulun VC, Schütz AC, Michel MM, Geisler WS, Gegenfurtner KR. Visual search under scotopic lighting conditions. Vision Res. 113, $155-168$ (2015).

77. Klein C, Fischer B. Instrumental and test-retest reliability of saccadic measures. Biol. Psychol. 68(3), 201-213 (2005).

78. Holmqvist K, Nyström M, Mulvey F. Eye tracker data quality: what it is and how to measure it. In: Proceedings of the Symposium on Eye Tracking Research and Applications. ACM, NY, USA, 45-52 (2012). https://dl.acm.org/citation.cfm?id=2168556

79. Straube A, Büttner U. Neuro-ophthalmology: Neuronal Control of Eye Movements. Karger Medical and Scientific Publishers, Basel, Switzerland (2007). https://www.karger.com/Book/Home/232644 
80. Ing E, Lee AG. eMedicine article on neuro-ophthalmic examination. https://emedicine.medscape.com/article/1820707-overview

81. Nyström M, Hansen DW, Andersson R, Hooge I. Why have microsaccades become larger? Investigating eye deformations and detection algorithms. Vision Res. 118, 17-24 (2016).

82. Poletti M, Rucci M. A compact field guide to the study of microsaccades: challenges and functions. Vision Res. 118, 83-97 (2016).

83. Mack DJ, Belfanti S, Schwarz U. The effect of sampling rate and lowpass filters on saccades - a modeling approach. Behav. Res. Methods 49(6), 2146-2162 (2017).

84. Fuchs AF. Saccadic and smooth pursuit eye movements in the monkey. J. Physiol. 191(3), 609-631 (1967).

85. Andersson R, Nyström M, Holmqvist K. Sampling frequency and eye-tracking measures: how speed affects durations, latencies, and more. J. Eye Mov. Res. 3(3)(6), 1-12 (2010).

86. Juhola M, Jäntti V, Pyykkö I. Effect of sampling frequencies on computation of the maximum velocity of saccadic eye movements. Biol. Cybern. 53(2), 67-72 (1985).

87. Wierts R, Janssen MJA, Kingma H. Measuring saccade peak velocity using a low-frequency sampling rate of $50 \mathrm{~Hz}$. IEEE Trans. Biomed. Eng. 55(12), 2840-2842 (2008).

88. Feit AM, Williams S, Toledo A et al. Toward everyday gaze input: accuracy and precision of eye tracking and implications for design. In: Proceedings of the 2017 Chi Conference on Human Factors in Computing Systems. ACM, NY, USA, 1118-1130 (2017). https://dl.acm.org/citation.cf m?id=3025599

89. Kolarik AJ, Margrain TH, Freeman TCA. Precision and accuracy of ocular following: influence of age and type of eye movement. Exp. Brain Res. 201(2), 271-282 (2010).

90. Armstrong RA. Visual dysfunction in Parkinson's disease. Int. Rev. Neurobiol. 134, 921-946 (2017).

91. Marmor MF, Brigell MG, McCulloch DL, Westall CA, Bach M. ISCEV standard for clinical electro-oculography (2010 update). Doc. Ophthalmol. 122(1), 1-7 (2011).

92. Chen R, Kalinli O. Interface using eye tracking contact lenses. US20120281181 (2011). http://ozlemkalinli.com/patents.htm

93. Nyström M, Holmqvist K. An adaptive algorithm for fixation, saccade, and glissade detection in eyetracking data. Behav. Res. Methods 42(1), 188-204 (2010).

94. Andersson R, Larsson L, Holmqvist K, Stridh M, Nyström M. One algorithm to rule them all? An evaluation and discussion of ten eye movement event-detection algorithms. Behav. Res. Methods 49(2), 616-637 (2017).

- This is a comprehensive study comparing different algorithms to extract ocular events.

95. Stuart S, Hickey A, Vitorio R et al. Eye-tracker algorithms to detect saccades during static and dynamic tasks: a structured review. Physiol. Meas. 40(2), 02TR01 (2019).

96. Bijvank JAN, Petzold A, Balk LJ et al. A standardized protocol for quantification of saccadic eye movements: DEMoNS. PLoS ONE 13(7), e0200695 (2018).

97. Owsley C, Sloane ME. Contrast sensitivity, acuity, and the perception of "real-world" targets. Br. J. Ophthalmol. 71(10), 791-796 (1987).

98. Cavallotti C, Cerulli L. Age-Related Changes of the Human Eye. Humana Press, NJ, USA (2008). https://link.springer.com/article/10.1007/s10522-008-9202-2

99. Lee WJ, Kim JH, Shin YU, Hwang S, Lim HW. Differences in eye movement range based on age and gaze direction. Eye 33, 1145-1151 (2019).

100. Bosten JM, Goodbourn PT, Bargary G et al. An exploratory factor analysis of visual performance in a large population. Vision Res. 141, 303-316 (2017).

101. Bonnet C, Hanuška J, Rusz J et al. Horizontal and vertical eye movement metrics: what is important? Clin. Neurophysiol. 124(11), 2216-2229 (2013).

102. Pelak VS. Ocular motility of aging and dementia. Curr. Neurol. Neurosci. Rep. 10(6), 440-447 (2010).

103. Calkins DJ. Age-related changes in the visual pathways: blame it on the axon. Investig. Ophthalmol. Vis. Sci. 54(14), ORSF37-ORSF41 (2013).

104. Formicola L, Marazzi G, Sassoon DA. The extraocular muscle stem cell niche is resistant to ageing and disease. Front. Aging Neurosci. 6, 328 (2014).

105. Yang Q, Kapoula Z. Aging does not affect the accuracy of vertical saccades nor the quality of their binocular coordination: a study of a special elderly group. Neurobiol. Aging 29(4), 622-638 (2008).

106. McLoon LK, Thorstenson KM, Solomon A, Lewis MP. Myogenic precursor cells in craniofacial muscles. Oral Dis. 13(2), 134-140 (2007).

107. Yeotikar NS, Zhu H, Markoulli M, Nichols KK, Naduvilath T, Papas EB. Functional and morphologic changes of meibomian glands in an asymptomatic adult population. Investig. Ophthalmol. Vis. Sci. 57(10), 3996-4007 (2016).

108. Nesmith B, Gupta A, Strange T, Schaal Y, Schaal S. Mathematical analysis of the normal anatomy of the aging fovea. Investig. Ophthalmol. Vis. Sci. 55(9), 5962-5966 (2014). 
109. Klein C, Fischer B, Hartnegg K, Heiss WH, Roth M. Optomotor and neuropsychological performance in old age. Exp. Brain Res. 135(2), 141-154 (2000).

110. Munoz DP, Broughton JR, Goldring JE, Armstrong IT. Age-related performance of human subjects on saccadic eye movement tasks. Exp. Brain Res. 121(4), 391-400 (1998).

111. Kerber KA, Ishiyama GP, Baloh RW. A longitudinal study of oculomotor function in normal older people. Neurobiol. Aging 27(9), 1346-1353 (2006).

112. Dowiasch S, Marx S, Einhäuser W, Bremmer F. Effects of aging on eye movements in the real world. Front. Hum. Neurosci. 9, 46 (2015).

113. Sun WS, Baker RS, Chuke JC et al. Age-related changes in human blinks: passive and active changes in eyelid kinematics. Investig. Ophthalmol. Vis. Sci. 38(1), 92-99 (1997).

114. der Werf F, Smit AE. The world according to blink: blinking and aging. In: Cavallotti, Carlo, Cerulli, Luciano (Eds). Age-Related Changes of the Human Eye. Humana Press, NJ, US319-341 (2008). https://www.springer.com/gp/book/9781934115558

115. Brockmole JR, Logie RH. Age-related change in visual working memory: a study of 55,753 participants aged 8-75. Front. Psychol. 4, 12 (2013).

116. Huang J, Gegenfurtner KR, Schutz AC, Billino J. Age effects on saccadic adaptation: evidence from different paradigms reveals specific vulnerabilities. J. Vis. 17(6), 1-18 (2017).

117. Meng Q, Wang B, Cui D et al. Age-related changes in local and global visual perception. J. Vis. 19(1(10)), 1-12 (2019).

118. Pilz KS, Miller L, Agnew HC. Motion coherence and direction discrimination in healthy aging. J. Vis. 17(1(31)), 1-12 (2017).

119. Roudaia E, Faubert J. Different effects of aging and gender on the temporal resolution in attentional tracking. J. Vis. 17(11(1)), 1-16 (2017).

120. Pitchaimuthu K, Nguyen BN, McKendrick AM. Aging alters intraocular but not interocular foveal center surround contrast suppression. J. Vis. 17(1(16)), 1-10 (2017).

121. Guest D, Howard CJ, Brown LA, Gleeson H. Aging and the rate of visual information processing. J. Vis. 15(14)(10), 1-25 (2015).

122. Rycroft SS, Giovannetti T, Shipley TF, Hulswit J, Divers R, Reilly J. Windows to functional decline: naturalistic eye movements in older and younger adults. Psychol. Aging 33(8), 1215 (2018).

123. Russell Poldrack. CognitiveAtlas. https://www.cognitiveatlas.org/tasks

124. Wolfe JM. Visual search. Curr. Biol. 20(8), R346-R349 (2010).

125. Wolfe JM. Guided search 2.0 a revised model of visual search. Psychon. Bull. Rev. 1(2), 202-238 (1994).

126. Trick LM, Enns JT. Lifespan changes in attention: the visual search task. Cogn. Dev. 13(3), 369-386 (1998).

127. Armstrong T, Olatunji BO. Eye tracking of attention in the affective disorders: a meta-analytic review and synthesis. Clin. Psychol. Rev. 32(8), 704-723 (2012).

128. Langner R, Eickhoff SB. Sustaining attention to simple tasks: a meta-analytic review of the neural mechanisms of vigilant attention. Psychol. Bull. 139(4), 870 (2013).

129. Beurskens R, Bock O. Age-related deficits of dual-task walking: a review. Neural Plast. 2012(Article ID 131608), 1-9 (2012).

130. Rand MK, Stelmach GE. Effect of aging on coordinated eye and hand movements with two-segment sequence. Motor Control. 16(4), 447-465 (2012).

131. Menant JC, St George RJ, Fitzpatrick RC, Lord SR. Impaired depth perception and restricted pitch head movement increase obstacle contacts when dual-tasking in older people. J. Gerontol. Ser. A Biomed. Sci. Med. Sci. 65(7), 751-757 (2010).

132. Berger L, Bernard-Demanze L. Age-related effects of a memorizing spatial task in the adults and elderly postural control. Gait Posture. 33(2), 300-302 (2011).

133. Soldan A, Pettigrew C, Moghekar A, Albert M, BIOCARD Research Team. Computerized cognitive tests are associated with biomarkers of Alzheimer's disease in cognitively normal individuals 10 years prior. J. Int. Neuropsychol. Soc. 22(10), 968-977 (2016).

134. Yamada Y, Kobayashi M. Detecting mental fatigue from eye-tracking data gathered while watching video: evaluation in younger and older adults. Artif. Intell. Med. 91, 39-48 (2018).

135. Stuart S, Lord S, Galna B, Rochester L. Saccade frequency response to visual cues during gait in Parkinson's disease: the selective role of attention. Eur. J. Neurosci. 47(7), 769-778 (2018).

136. Bergstrom JCR, Olmsted-Hawala EL, Jans ME. Age-related differences in eye tracking and usability performance: website usability for older adults. Intl J. Human-Computer Interact. 29(8), 541-548 (2013).

137. Merat N, Jamson AH. The effect of three low-cost engineering treatments on driver fatigue: a driving simulator study. Accid. Anal. Prev. 50, 8-15 (2013).

138. Hüttermann S, Bock O, Memmert D. The breadth of attention in old age. Ageing Res. 3(1), e10 (2012).

139. Allard ES, Wadlinger HA, Isaacowitz DM. Positive gaze preferences in older adults: assessing the role of cognitive effort with pupil dilation. Neuropsychol. Dev. Cogn. B Aging Neuropsychol. Cogn. 17(3), 296-311 (2010). 
140. Piquado T, Isaacowitz D, Wingfield A. Pupillometry as a measure of cognitive effort in younger and older adults. Psychophysiology 47(3), 560-569 (2010).

141. Coe BC, Munoz DP. Mechanisms of saccade suppression revealed in the anti-saccade task. Philos. Trans. R. Soc. B Biol. Sci. 372(1718), 20160192 (2017).

142. Munoz DP, Armstrong IT, Hampton KA, Moore KD. Altered control of visual fixation and saccadic eye movements in attention-deficit hyperactivity disorder. J. Neurophysiol. 90(1), 503-514 (2003).

143. Schwerdtfeger RMH, Alahyane N, Brien DC, Coe BC, Stroman PW, Munoz DP. Preparatory neural networks are impaired in adults with attention-deficit/hyperactivity disorder during the antisaccade task. NeuroImage Clin. 2, 63-78 (2013).

144. Witiuk K, Fernandez-Ruiz J, McKee R et al. Cognitive deterioration and functional compensation in ALS measured with fMRI using an inhibitory task. J. Neurosci. 34(43), 14260-14271 (2014).

145. Antoniades CA, Demeyere N, Kennard C, Humphreys GW, Hu MT. Antisaccades and executive dysfunction in early drug-naive Parkinson's disease: the discovery study. Mov. Disord. 30(6), 843-847 (2015).

146. Amador SC, Hood AJ, Schiess MC, Izor R, Sereno AB. Dissociating cognitive deficits involved in voluntary eye movement dysfunctions in Parkinson's disease patients. Neuropsychologia 44(8), 1475-1482 (2006).

147. Brooks SH, Klier EM, Red SD et al. Slowed prosaccades and increased antisaccade errors as a potential behavioral biomarker of multiple system atrophy. Front. Neurol. 8, 261 (2017).

148. Shakespeare TJ, Kaski D, Yong KXX et al. Abnormalities of fixation, saccade and pursuit in posterior cortical atrophy. Brain 138(7), 1976-1991 (2015).

149. Bowling A, Draper A. Using saccadic eye movements to assess cognitive decline with ageing. In: Horsley M, Eliot M, Knight BA, Reilly R (Eds). Current Trends in Eye Tracking Research. Springer International Publishing, Cham, Switzerland, 237-244 (2014).

150. Alichniewicz KK, Brunner F, Klünemann HH, Greenlee MW. Neural correlates of saccadic inhibition in healthy elderly and patients with amnestic mild cognitive impairment. Front. Psychol. 4, 467 (2013).

151. Yang Q, Wang T, Su N, Xiao S, Kapoula Z. Specific saccade deficits in patients with Alzheimer's disease at mild to moderate stage and in patients with amnestic mild cognitive impairment. Age (Omaha) 35(4), 1287-1298 (2013).

152. Wang M, Gamo NJ, Yang Y et al. Neuronal basis of age-related working memory decline. Nature 476(7359), 210 (2011).

153. Morita K, Miura K, Fujimoto M et al. Eye movement as a biomarker of schizophrenia: using an integrated eye movement score. Psychiatry Clin. Neurosci. 71(2), 104-114 (2017).

154. Damilou A, Apostolakis S, Thrapsanioti E, Theleritis C, Smyrnis N. Shared and distinct oculomotor function deficits in schizophrenia and obsessive compulsive disorder. Psychophysiology 53(6), 796-805 (2016).

155. Forbes PA, Siegmund GP, Schouten AC, Blouin J-S. Task, muscle and frequency dependent vestibular control of posture. Front. Integr. Neurosci. 8, 94 (2015).

156. Hyon JY, Yeo HE, Seo J-M, Lee IB, Lee JH, Hwang J-M. Objective measurement of distance visual acuity determined by computerized optokinetic nystagmus test. Invest. Ophthalmol. Vis. Sci. 51(2), 752-757 (2010).

157. Atkinson J. Human visual development over the first 6 months of life. A review and a hypothesis. Hum. Neurobiol. 3(2), 61-74 (1984).

158. van der W, el P, van Steenbergen H. Pupil dilation as an index of effort in cognitive control tasks: a review. Psychon. Bull. Rev. 25(6), 2005-2015 (2018).

159. Rondeel E, Van Steenbergen H, Holland R, van Knippenberg A. A closer look at cognitive control: differences in resource allocation during updating, inhibition and switching as revealed by pupillometry. Front. Hum. Neurosci. 9, 494 (2015).

160. Anderson TJ, MacAskill MR. Eye movements in patients with neurodegenerative disorders. Nat. Rev. Neurol. 9(2), 74-85 (2013).

161. Lim JKH, Li Q-X, He Z et al. The eye as a biomarker for Alzheimer's disease. Front. Neurosci. 10, 536 (2016).

\section{- This reference provides information on biomarkers for Alzheimer's disease with a focus on eyes.}

162. Pavisic IM, Firth NC, Parsons S et al. Eyetracking metrics in young onset Alzheimer's disease: a window into cognitive visual functions. Front. Neurol. 8, 377 (2017).

163. Alberdi A, Aztiria A, Basarab A. On the early diagnosis of Alzheimer's disease from multimodal signals: a survey. Artif. Intell. Med. 71 , $1-29$ (2016).

164. Bittner DM, Wieseler I, Wilhelm H, Riepe MW, Müller NG. Repetitive pupil light reflex: potential marker in Alzheimer's disease? J. Alzheimer's Dis. 42(4), 1469-1477 (2014).

165. Molitor RJ, Ko PC, Ally BA. Eye movements in Alzheimer's disease. J. Alzheimer's Dis. 44(1), 1-12 (2015).

166. Cerquera-Jaramillo MA, Nava-Mesa MO, González-Reyes RE, Tellez-Conti C, De-la-Torre A. Visual features in Alzheimer's disease: from basic mechanisms to clinical overview. Neural Plast. 2018(Article ID 2941783), 1-21 (2018).

167. Crawford TJ. The disengagement of visual attention in Alzheimer's disease: a longitudinal eye-tracking study. Front. Aging Neurosci. 7 , 118 (2015). 
168. Beltrán J, García-Vázquez MS, Benois-Pineau J, Gutierrez-Robledo LM, Dartigues J-F. Computational techniques for eye movements analysis towards supporting early diagnosis of Alzheimer's disease: a review. Comput. Math. Methods Med. 2018(Article ID 2676409), $1-13$ (2018).

169. Patel SS, Jankovic J, Hood AJ, Jeter CB, Sereno AB. Reflexive and volitional saccades: biomarkers of Huntington disease severity and progression. J. Neurol. Sci. 313(1-2), 35-41 (2012).

170. Wiecki TV, Antoniades CA, Stevenson A et al. A computational cognitive biomarker for early-stage Huntington's disease. PLoS ONE 11(2), e0148409 (2016).

- This reference provides information on biomarkers for Huntington's disease.

171. Perneczky R, Ghosh BCP, Hughes L, Carpenter RHS, Barker RA, Rowe JB. Saccadic latency in Parkinson's disease correlates with executive function and brain atrophy, but not motor severity. Neurobiol. Dis. 43(1), 79-85 (2011).

172. Rafal RD. Oculomotor functions of the parietal lobe: effects of chronic lesions in humans. Cortex 42(5), 730-739 (2006).

173. Mort DJ, Perry RJ, Mannan SK et al. Differential cortical activation during voluntary and reflexive saccades in man. Neuroimage 18(2), 231-246 (2003).

174. Pierrot-Deseilligny C, Israel I, Berthoz A, Rivaud S, Gaymard B. Role of the different frontal lobe areas in the control of the horizontal component of memory-guided saccades in man. Exp. Brain Res. 95(1), 166-171 (1993).

175. Pinkhardt EH, Kassubek J. Ocular motor abnormalities in Parkinsonian syndromes. Parkinsonism Relat. Disord. 17(4), 223-230 (2011).

176. Rivaud-Péchoux S, Vermersch A-I, Gaymard B et al. Improvement of memory guided saccades in parkinsonian patients by high frequency subthalamic nucleus stimulation. J. Neurol. Neurosurg. Psychiatry 68(3), 381-384 (2000).

177. Sauleau P, Pollak P, Krack P et al. Subthalamic stimulation improves orienting gaze movements in Parkinson's disease. Clin. Neurophysiol. 119(8), 1857-1863 (2008).

178. Temel Y, Visser-Vandewalle V, Carpenter RHS. Saccadometry: a novel clinical tool for quantification of the motor effects of subthalamic nucleus stimulation in Parkinson's disease. Exp. Neurol. 216(2), 481-489 (2009).

179. Temel Y, Visser-Vandewalle V, Carpenter RHS. Saccadic latency during electrical stimulation of the human subthalamic nucleus. Curr. Biol. 18(10), R412-R414 (2008).

180. Camacho PB, Carbonari R, Shen S, Zadikoff C, Kramer AF, Lopez-Ortiz C. Voluntary saccade training protocol in persons with Parkinson's disease and healthy adults. Front. Aging Neurosci. 11, 77 (2019).

181. Krejtz K, Duchowski A, Krejtz I, Szarkowska A, Kopacz A. Discerning ambient/focal attention with coefficient k. ACM Trans. Appl. Percept. 13(3), 11 (2016).

182. Anderson T, Luxon L, Quinn N, Daniel S, David Marsden C, Bronstein A. Oculomotor function in multiple system atrophy: clinical and laboratory features in 30 patients. Mov. Disord. Off. J. Mov. Disord. Soc. 23(7), 977-984 (2008).

183. Hollands M, Hollands K, Rietdyk S. Visual control of adaptive locomotion and changes due to natural ageing. In: Locomotion and Posture in Older Adults. Barbieri FA, Vitório R (Eds). Springer, Cham, Switzerland, 55-72 (2017).https://link.springer.com/book/10.1007/978-3-319-48980-3

184. Coubard OA. Fall prevention modulates decisional saccadic behavior in aging. Front. Aging Neurosci. 4, 18 (2012).

185. Berg WP, Alessio HM, Mills EM, Tong C. Circumstances and consequences of falls in independent community-dwelling older adults. Age. Ageing 26(4), 261-268 (1997).

186. Blake AJ, Morgan K, Bendall MJ et al. Falls by elderly people at home: prevalence and associated factors. Age. Ageing 17(6), 365-372 (1988).

187. Zalewski CK. Aging of the human vestibular system. In: Seminars in Hearing. Thieme Medical Publishers, NY, USA 175-196 (2015). https://www.ncbi.nlm.nih.gov/pmc/articles/PMC4906308/

188. Irving EL, Steinbach MJ, Lillakas L, Babu RJ, Hutchings N. Horizontal saccade dynamics across the human life span. Investig. Ophthalmol. Vis. Sci. 47(6), 2478-2484 (2006).

189. Peltsch A, Hemraj A, Garcia A, Munoz DP. Age-related trends in saccade characteristics among the elderly. Neurobiol. Aging 32(4), 669-679 (2011).

190. Sharpe JA, Sylvester TO. Effect of aging on horizontal smooth pursuit. Invest. Ophthalmol. Vis. Sci. 17(5), 465-468 (1978).

191. Anson ER, Bigelow RT, Carey JP et al. Aging increases compensatory saccade amplitude in the video head impulse test. Front. Neurol. 7 , $113(2016)$

192. Ben-David BM, Chambers CG, Daneman M, Pichora-Fuller MK, Reingold EM, Schneider BA. Effects of aging and noise on real-time spoken word recognition: evidence from eye movements. J. Speech, Lang. Hear. Res. 54(1), 243-62 2011).

193. Ayasse ND, Lash A, Wingfield A. Effort not speed characterizes comprehension of spoken sentences by older adults with mild hearing impairment. Front. Aging Neurosci. 8, 329 (2017).

194. Wendt D, Kollmeier B, Brand T. How hearing impairment affects sentence comprehension: using eye fixations to investigate the duration of speech processing. Trends Hear. 19, 1-18 (2015). 
195. Dobreva MS, O’Neill WE, Paige GD. Influence of aging on human sound localization. J. Neurophysiol. 105(5), 2471-2486 (2011).

196. Cui QN, O’Neill WE, Paige GD. Advancing age alters the influence of eye position on sound localization. Exp. Brain Res. 206(4), 371-379 (2010).

197. Ibáñez V, Silva J, Cauli O. A survey on sleep assessment methods. PeerJ 6, e4849 (2018).

198. Pace-Schott EF, Spencer RMC. Chapter 5 - age-related changes in the cognitive function of sleep. Prog. Brain. Res. 191, 75-89 (2011).

199. Mander BA, Rao V, Lu B et al. Prefrontal atrophy, disrupted NREM slow waves and impaired hippocampal-dependent memory in aging. Nat. Neurosci. 16(3), 357 (2013).

200. Boeve BF, Molano JR, Ferman TJ et al. Validation of the Mayo Sleep Questionnaire to screen for REM sleep behavior disorder in an aging and dementia cohort. Sleep Med. 12(5), 445-453 (2011).

201. Morgan JC, Mehta SH, Sethi KD. Biomarkers in Parkinson's disease. Curr. Neurol. Neurosci. Rep. 10(6), 423-430 (2010).

202. Scullin MK, Bliwise DL. Sleep, cognition, and normal aging: integrating a half century of multidisciplinary research. Perspect. Psychol. Sci. 10(1), 97-137 (2015).

203. Bandelow B, Michaelis S. Epidemiology of anxiety disorders in the 21st century. Dialogues Clin. Neurosci. 17(3), 327 (2015).

204. Nakazato K, Shimonaka Y. The Japanese state-trait anxiety inventory: age and sex differences. Percept. Mot. Skills. 69(2), 611-617 (1989).

205. Prenderville JA, Kennedy PJ, Dinan TG, Cryan JF. Adding fuel to the fire: the impact of stress on the ageing brain. Trends Neurosci. 38(1), 13-25 (2015).

206. Maurya PK, Noto C, Rizzo LB et al. The role of oxidative and nitrosative stress in accelerated aging and major depressive disorder. Prog. Neuropsychopharmacol. Biol. Psychiatry 65, 134-144 (2016).

207. Ferrara M, Langiano E, Di Brango T, Di Cioccio L, Bauco C, De Vito E. Prevalence of stress, anxiety and depression in with Alzheimer caregivers. Health Qual. Life Outcomes 6(1), 93 (2008).

208. He Y, Chen R, Wang J et al. Neurocognitive impairment is correlated with oxidative stress in patients with moderate-to-severe obstructive sleep apnea hypopnea syndrome. Respir. Med. 120, 25-30 (2016).

209. Polta SA, Fenzl T, Jakubcakova V, Kimura M, Yassouridis A, Wotjak CT. Prognostic and symptomatic aspects of rapid eye movement sleep in a mouse model of posttraumatic stress disorder. Front. Behav. Neurosci. 7, 60 (2013).

210. Shapiro F. Eye Movement Desensitization and Reprocessing (EMDR) Therapy: Basic Principles, Protocols, and Procedures. Guilford Press, NY, USA (1995).

211. de Jongh A, Ernst R, Marques L, Hornsveld H. The impact of eye movements and tones on disturbing memories involving PTSD and other mental disorders. J. Behav. Ther. Exp. Psychiatry 44(4), 477-483 (2013).

212. Chen L, Zhang G, Hu M, Liang X. Eye movement desensitization and reprocessing versus cognitive-behavioral therapy for adult posttraumatic stress disorder: systematic review and meta-analysis. J. Nerv. Ment. Dis. 203(6), 443-451 (2015).

213. Hannula DE, Althoff RR, Warren DE, Riggs L, Cohen NJ, Ryan JD. Worth a glance: using eye movements to investigate the cognitive neuroscience of memory. Front. Hum. Neurosci. 4, 166 (2010).

214. Marandi RZ, Sabzpoushan SH. Using eye movement analysis to study auditory effects on visual memory recall. Basic Clin. Neurosci. 5(1), 55-65 (2014).

215. Marandi RZ, Sabzpoushan SH. Qualitative modeling of the decision-making process using electrooculography. Behav. Res. Methods 47(4), 1404-1412 (2014).

216. Boot WR, Stothart C, Charness N. Improving the safety of aging road users: a mini-review. Gerontology 60(1), 90-96 (2014).

217. Merhav M, Riemer M, Wolbers T. Spatial updating deficits in human aging are associated with traces of former memory representations. Neurobiol. Aging 76, 53-61 (2019).

218. Marchette SA, Yerramsetti A, Burns TJ, Shelton AL. Spatial memory in the real world: long-term representations of everyday environments. Mem. Cognit. 39(8), 1401 (2011).

219. Kline JE, Poggensee K, Ferris DP. Your brain on speed: cognitive performance of a spatial working memory task is not affected by walking speed. Front. Hum. Neurosci. 8, 288 (2014).

220. Rowe G, Hasher L, Turcotte J. Age differences in visuospatial working memory. Psychol. Aging 23(1), 79 (2008).

221. Dobreva MS, O’Neill WE, Paige GD. Influence of age, spatial memory, and ocular fixation on localization of auditory, visual, and bimodal targets by human subjects. Exp. Brain Res. 223(4), 441-455 (2012).

222. Walle KM, Nordvik JE, Espeseth T, Becker F, Laeng B. Multiple object tracking and pupillometry reveal deficits in both selective and intensive attention in unilateral spatial neglect. J. Clin. Exp. Neuropsychol. 41(3), 270-289 (2019).

223. Fung HH, Lu M, Isaacowitz DM. Aging and attention: meaningfulness may be more important than valence. Psychol. Aging $34(1), 85$ (2019).

224. Ebner NC, He YI, Johnson MK. Age and emotion affect how we look at a face: visual scan patterns differ for own-age versus other-age emotional faces. Cogn. Emot. 25(6), 983-997 (2011). 
225. Whitford V, Titone D. Eye movements and the perceptual span during first-and second-language sentence reading in bilingual older adults. Psychol. Aging 31(1), 58 (2016).

226. Harris D (Ed.). Engineering Psychology and Cognitive Ergonomics. Springer, Cham, Switzerland (2017).

227. Bröhl C, Theis S, Rasche P, Wille M, Mertens A, Schlick CM. Neuroergonomic analysis of perihand space: effects of hand proximity on eye-tracking measures and performance in a visual search task. Behav. Inf. Technol. 36(7), 737-744 (2017).

228. Rizzo M, Parasuraman R. Applied perception and neuroergonomics. In: The Cambridge Handbook of Applied Perception Research. Hoffman RR, Hancock PA, Scerbo MW, Parasuraman R, Szalma JL (Eds). Cambridge University Press, Cambridge, United Kingdom 79-104 (2015).

229. Peruzzini M, Pellicciari M. A framework to design a human-centred adaptive manufacturing system for aging workers. Adv. Eng. Informatics 33, 330-349 (2017).

230. Madeleine P, Marandi RZ, Norheim KL, Vuillerme N, Samani A. Characterization of the dynamics of sitting during a sustained and mentally demanding computer task. In: Congress of the International Ergonomics Association. Bagnara S, Tartaglia R, Albolino S, Alexander TFY (Eds). Springer Nature Switzerland AG, Cham, Switzerland, 338-344 (2018). https://link.springer.com/book/10.1007/978-3-319-96071-5

231. Norheim KL, Samani A, Bønløkke JH, Omland Ø, Madeleine P. The effects of age and musculoskeletal pain on force variability among manual workers. Hum. Mov. Sci. 64, 19-27 (2019).

232. Young MS, Brookhuis KA, Wickens CD, Hancock PA. State of science: mental workload in ergonomics. Ergonomics 58(1), 1-17 (2015).

233. Wikman A-S, Summala H. Aging and time-sharing in highway driving. Optom. Vis. Sci. 82(8), 716-723 (2005).

234. Sun Q, Xia J, Nadarajah N, Falkmer T, Foster J, Lee H. Assessing drivers' visual-motor coordination using eye tracking, GNSS and GIS: a spatial turn in driving psychology. J. Spat. Sci. 61(2), 299-316 (2016).

235. Coughlin JF, Reimer B, Mehler B. Monitoring, managing, and motivating driver safety and well-being. IEEE Pervasive Comput. 10(3), 14-21 (2011).

236. Schmidt K, Gamer M, Forkmann K, Bingel U. Pain affects visual orientation: an eye-tracking study. J. Pain. 19(2), 135-145 (2018).

237. Johnson D, Deterding S, Kuhn K-A, Staneva A, Stoyanov S, Hides L. Gamification for health and wellbeing: a systematic review of the literature. Internet Interv. 6, 89-106 (2016).

238. Qiu Y, Li KM, Neoh EC et al. Fun-Knee ${ }^{\mathrm{TM}}$ : a novel smart knee sleeve for total-knee-replacement rehabilitation with gamification. In: 2017 IEEE 5th International Conference on Serious Games and Applications for Health

(SeGAH). 1-8 (2017). http://www.ntulily.org/wp-content/uploads/conference/Fun-Knee_A_Novel_Smart_Knee_Sleeve_for_Total-Kne e-Replacement_Rehabilitation_with_Gamification_accepted.pdf

239. Trost Z, Zielke M, Guck A et al. The promise and challenge of virtual gaming technologies for chronic pain: the case of graded exposure for low back pain. Pain Manag. 5(3), 197-206 (2015).

240. Zwakhalen SMG, Hamers JPH, Abu-Saad HH, Berger MPF. Pain in elderly people with severe dementia: a systematic review of behavioural pain assessment tools. BMC Geriatr. 6(1), 3 (2006).

241. Üstün TB, Rehm J, Chatterji S et al. Multiple-informant ranking of the disabling effects of different health conditions in 14 countries. Lancet 354(9173), 111-115 (1999).

242. Laursen TM, Munk-Olsen T, Vestergaard M. Life expectancy and cardiovascular mortality in persons with schizophrenia. Curr. Opin. Psychiatry 25(2), 83-88 (2012).

243. van Os J, Kapur S. Schizophrenia. Lancet 374(9690), 635-645 (2009).

244. Saha S, Chant D, McGrath J. A systematic review of mortality in schizophrenia: is the differential mortality gap worsening over time? Arch. Gen. Psychiatry 64(10), 1123-1131 (2007).

245. Grace PM, Stanford T, Gentgall M, Rolan PE. Utility of saccadic eye movement analysis as an objective biomarker to detect the sedative interaction between opioids and sleep deprivation in opioid-naive and opioid-tolerant populations. J. Psychopharmacol. 24(11), $1631-1640$ (2010).

246. Vidal MM, Turner J, Bulling A, Gellersen H. Wearable eye tracking for mental health monitoring. Comput. Commun. 35(11), 1306-1311 (2012).

247. Jeste D V, Palmer BW. A call for a new positive psychiatry of ageing. Br. J. Psychiatry 202(2), 81-83 (2013).

248. Mishra J, Gazzaley A. Harnessing the neuroplastic potential of the human brain \& the future of cognitive rehabilitation. Front. Hum. Neurosci. 8, 218 (2014).

249. Thiagarajan P, Ciuffreda KJ. Versional eye tracking in mild traumatic brain injury (mTBI): effects of oculomotor training (OMT). Brain Inj. 28(7), 930-943 (2014).

250. Paquette C, Fung J. Old age affects gaze and postural coordination. Gait Posture 33(2), 227-232 (2011).

251. Farah R, Haraty H, Salame Z, Fares Y, Ojcius DM, Sadier NS. Salivary biomarkers for the diagnosis and monitoring of neurological diseases. Biomed. J. 41(2), 63-87 (2018). 
252. Basak I, Patil KS, Alves G, Larsen JP, Møller SG. microRNAs as neuroregulators, biomarkers and therapeutic agents in neurodegenerative diseases. Cell. Mol. Life Sci. 73(4), 811-827 (2016).

253. Yetton BD, Niknazar M, Duggan KA et al. Automatic detection of rapid eye movements (REMs): a machine learning approach. $J$. Neurosci. Methods 259, 72-82 (2016).

254. Korda AI, Asvestas PA, Matsopoulos GK, Ventouras EM, Smyrnis N. Automatic identification of eye movements using the largest lyapunov exponent. Biomed. Signal Process. Control. 41, 10-20 (2018).

255. Aştefănoaei C, Creangă D, Pretegiani E, Optican LM, Rufa A. Dynamical complexity analysis of saccadic eye movements in two different psychological conditions. Rom. Reports Phys. 66(4), 1038 (2014).

256. Wu S-L, Liao L-D, Lu S-W, Jiang W-L, Chen S-A, Lin C-T. Controlling a human-computer interface system with a novel classification method that uses electrooculography signals. IEEE Trans. Biomed. Eng. 60(8), 2133-2141 (2013).

257. Harezlak K, Kasprowski P. Searching for chaos evidence in eye movement signals. Entropy 20(1), 32 (2018).

258. Onorati F, Mainardi LT, Sirca F, Russo V, Barbieri R. Nonlinear analysis of pupillary dynamics. Biomed. Eng. Tech. 61(1), 95-106 (2016).

259. Kim S, Yeom S, Kwon O-J, Shin D, Shin D. Ubiquitous healthcare system for analysis of chronic patients' biological and lifelog data. IEEE Access. 6, 8909-8915 (2018).

260. da Costa CA, Pasluosta CF, Eskofier B, da Silva DB, da Rosa Righi R. Internet of health things: toward intelligent vital signs monitoring in hospital wards. Artif. Intell. Med. 89, 61-69 (2018).

261. Engineer A, Sternberg EM, Najafi B. Designing interiors to mitigate physical and cognitive deficits related to aging and to promote longevity in older adults: a review. Gerontology 64(6), 612-622 (2018).

262. Kricka LJ. History of disruptions in laboratory medicine: what have we learned from predictions? Clin. Chem. Lab. Med. 57(3), 308-311 (2019).

263. Gatouillat A, Badr Y, Massot B, Sejdić E. Internet of medical things: a review of recent contributions dealing with cyber-physical systems in medicine. IEEE Internet Things J. 5(5), 3810-3822 (2018).

264. Topol E. The Patient will See You Now: the Future of Medicine is in Your Hands. Basic Books, NY, USA (2015).

265. Leuenberger MN, Loss D. Quantum computing in molecular magnets. Nature 410(6830), 789-793 (2001).

266. Mohseni M, Read P, Neven H et al. Commercialize quantum technologies in five years. Nat. News 543(7644), 171-174 (2017).

267. Barends R, Shabani A, Lamata L et al. Digitized adiabatic quantum computing with a superconducting circuit. Nature 534(7606), 222 (2016).

268. West DM. How 5G technology enables the health internet of things. Brookings Cent. Technol. Innov. 3, 1-20 (2016).

269. Chen M, Yang J, Hao Y, Mao S, Hwang K. A 5G cognitive system for healthcare. Big Data Cogn. Comput. 1(1), 2 (2017).

270. Bozomitu RG, Niţă L, Cehan V et al. A new integrated system for assistance in communicating with and telemonitoring severely disabled patients. Sensors 19(9), 2026 (2019). 